\title{
A extrajudicialização dos procedimentos: um caminho necessário
}

\author{
The extrajudicialization of procedures: a necessary path \\ La extrajudicialización de procedimientos: un camino necesario
}

Recebido: 25/08/2021 | Revisado: 03/09/2021 | Aceito: 09/09/2021 | Publicado: 12/09/2021

Flávia Muraro Rodrigues

ORCID: https://orcid.org/0000-0003-3094-1453 Centro Universitário da Grande Dourados, Brasil

E-mail: flavia.muraro@hotmail.com

Gilberto Ferreira Marchetti Filho

ORCID: https://orcid.org/0000-0002-5602-2538

Universidade Presbiteriana Mackenzie, Brasil E-mail: gilberto.marchetti@unigran.br

Miriam Fecchio Chueiri

ORCID: https://orcid.org/0000-0003-4658-5414

Universidade Paranaense, Brasil

E-mail: mfecchio@prof.unipar.br

\begin{abstract}
Resumo
À medida em que os conflitos sociais se modificam, tornando-se mais complexos, emerge como meio adequado para a pacificação de tais conflitos a extrajudicialização. O presente trabalho tem como objetivo analisar o fenômeno da extrajudicialização dos conflitos, assim como sua adequação ao âmbito jurídico brasileiro, comparando-a com os demais meios de solução de conflito e demonstrando seus pontos positivos, bem como as desvantagens. Para isso, busca-se, por meio de revisão bibliográfica, bem como dados coletados por órgãos oficiais e da legislação brasileira, fazer uma breve análise do sistema judiciário brasileiro e da realidade processual após o Código de Processo Civil de 2015 e a necessidade de adequação dos meios de solução de conflitos na busca pela pacificação social, tendo em vista a extrajudicialização como uma forma de resolução condizente com a atual realidade social. Como resultado, apresentou-se a importância da extrajudicialização de procedimentos, dentro do campo da efetividade, eficácia e adequação na solução de litígios, com o objetivo de diminuir o número de processos no Poder Judiciário, bem como promover a solução de conflitos de forma célere, efetiva e adequada à sua realidade. Lado outro, também se apresentou os principais percalços para uma utilização mais ampla dos procedimentos extrajudiciais na solução dos litígios.
\end{abstract}

Palavras-chave: Extrajudicialização; Conflitos sociais; Pacificação social; Sistema judiciário.

\begin{abstract}
As social conflicts change, becoming more complex, extrajudicialization emerges as an adequate means for pacifying such conflicts. This paper aims to analyze the phenomenon of extrajudicialization of conflicts, as well as its adequacy to the Brazilian legal framework, comparing it with other means of conflict resolution and demonstrating its positive points, as well as its disadvantages. For this, through a literature review, as well as data collected by official bodies and Brazilian legislation, it is sought to make a brief analysis of the Brazilian judicial system and the procedural reality after the 2015 Code of Civil Procedure and the need for adaptation of the means of conflict resolution in the search for social pacification, considering extrajudicialization as a form of resolution consistent with the current social reality. As a result, the importance of extrajudicialization of procedures was presented, within the field of effectiveness, efficiency and adequacy in the resolution of disputes, with the objective of reducing the number of cases in the Judiciary Branch, as well as promoting the swift resolution of conflicts, effective and adequate to your reality. On the other hand, the main obstacles to a wider use of extrajudicial procedures in the resolution of disputes were also presented.
\end{abstract}

Keywords: Extrajudicialization; Social conflicts; Social pacification; Judicial system.

\section{Resumen}

A medida que los conflictos sociales cambian y se vuelven más complejos, la extrajudicialización emerge como un medio adecuado para pacificar tales conflictos. Este trabajo tiene como objetivo analizar el fenómeno de la extrajudicialización de conflictos, así como su adecuación al marco legal brasileño, comparándolo con otros medios de resolución de conflictos y demostrando sus puntos positivos, así como sus desventajas. Para ello, a través de una revisión de la literatura, así como de los datos recolectados por los organismos oficiales y la legislación brasileña, se busca hacer un breve análisis del sistema judicial brasileño y la realidad procesal posterior al Código de Procedimiento Civil de 2015 y la necesidad de adecuación de los medios de resolución de conflictos en la búsqueda de la pacificación social, considerando la extrajudicialización como una forma de resolución acorde con la realidad 
social actual. Como resultado, se presentó la importancia de la extrajudicialización de los procedimientos, dentro del campo de la efectividad, eficiencia y adecuación en la resolución de controversias, con el objetivo de reducir el número de casos en el Poder Judicial, así como promover la pronta resolución de conflictos, efectivos y adecuados a su realidad. Por otro lado, también se presentaron los principales obstáculos para un uso más amplio de los procedimientos extrajudiciales en la resolución de controversias.

Palabras clave: Extrajudicialización; Conflictos sociales; Pacificación social; Sistema judicial.

\section{Introdução}

Não é recente o debate na cena jurídica sobre a morosidade do Poder Judiciário, ocasionado pelo grande volume de litígios que se ingressam diariamente. Assim como também não é a busca por meios que minimizem os percalços que a grande quantidade de processos e a lentidão do Judiciário causam na solução do conflito.

A par disso, surge com o Código de Processo Civil de 2015 um novo paradigma do processo, pautado na necessidade de adequação dos meios de solução de conflitos, em busca da pacificação social. Nesse contexto, o processo passa a ser visto como mais um meio de solução, ao lado de outros de igual importância, como a conciliação, a mediação e a arbitragem.

Ainda nesse campo de visada, o Código de Processo Civil alargou ainda mais a importância de um fenômeno que tem ganhado força nos últimos anos: a desjudicialização ou extrajudicialização dos conflitos, ou seja, a possibilidade de se solucionar determinados conflitos em cartórios extrajudiciais.

Nessa trilha, a extrajudicialização passou a ser um instrumento que permite deslocar a solução de determinados conflitos da seara judicial, possibilitando a tramitação de procedimentos determinados fora deste âmbito, com o fim de oferecer celeridade, efetividade e melhor adequação.

Deveras, seus mecanismos, no atual quadro da sociedade, se mostram de suma importância, já que as expectativas para desafogar o sistema judiciário crescem na mesma medida que os conflitos sociais surgem e se amplificam.

Todavia, a extrajudicialização não está totalmente adequada ao sistema jurídico, ainda que os conflitos sociais cresçam na medida em que a sociedade se desenvolve, o que gera certa insegurança e desconfiança na busca tutela extrajudicial para se esquivar da morosidade do Poder Judiciário.

Dessa forma, tendo em vista que a via extrajudicial busca a resolução de conflitos de maneira mais simples e célere, é preciso que haja a inserção deste instituto como opção viável à pacificação social, de maneira que os procedimentos correrão de forma precisa, garantindo segurança ao tutelado.

Diante desse cenário, a pesquisa se pautou em apresentar, no campo da problemática, de forma singela, quais os benefícios da utilização de meios desjudicializados de solução de conflitos, tendo em vista a celeridade, efetividade e adequação na busca pela pacificação social, bem assim problemas que a extrajudicialização enfrenta para ter maior adesão da população e profissionais do direito.

Tendo esse mote, esse artigo tem por objetivo analisar o fenômeno da extrajudicialização, bem como a necessidade de sua adequação ao sistema judiciário brasileiro e comparando as vantagens e desvantagens de utilizar a via extrajudicial como meio adequado a resolução de conflitos para, ao final, explanar os problemas enfrentados pelo Poder Judiciário brasileiro.

Para tanto, o texto, em primeiro, apresenta o fenômeno crescente da desjudicialização dos conflitos, bem como a necessidade de se analisar tal fenômeno com busca pela adequação dos meios de solução de conflitos em vista da pacificação social.

Após, adentrando nos objetivos, apresentará uma ideia das vantagens e possibilidades que a via extrajudicial pode oferecer na solução do conflito de forma adequada, dentro da celeridade e efetividade que se busca, bem como uma perspectiva de um dos principais problemas enfrentados para que a solução extrajudicial do conflito seja efetivamente adotada pela sociedade. 


\section{Metodologia}

No campo da metodologia adotada nesta pesquisa, diante do tema, problema e objetivo propostos, esta basicamente se organizará em exploratória descritiva e jurídico-projetivo (ou jurídico-prospectivo). Exploratória por ter como objetivo apresentar uma ideia ou esclarecimento conceitual acerca dos institutos interligados, estabelecendo prioridades para futuras pesquisas, além de procurar obter informações sobre possibilidades práticas no tema propostos dentro da realização das pesquisas (Selltiz et al, 1974, p. 60).

Importante destacar que, para o quanto necessário, pesquisas exploratórias proporcionam a visão geral acerca de determinado fato, realizado especialmente quando se trata de tema pouco explorado e torna-se mais difícil sobre ele formular hipóteses causais precisas e operacionalizáveis (Gil, 1999, p. 43).

Por sua vez, o tipo jurídico-projetivo parte de premissas e condições vigentes para detectar tendências futuras de determinado instituto jurídico ou determinado campo normativo específico, correlacionando dados para montagem de cenários jurídicos, atuais e futuros (Gustin et. al, 2006, p. 29-30).

Tendo isso em vista, o presente estudo teve por objetivo analisar o fenômeno da extrajudicialização da resolução de conflitos, vivenciado no sistema judicial brasileiro a partir de 2010, notadamente com a criação de leis que possibilitaram a solução de conflito por meio extrajudicial, principalmente em cartórios extrajudiciais.

Diante disso, buscou-se verificar as origens desse movimento, bem como o que ele representa, quais os impactos dele na solução de conflitos de forma adequada, bem como a efetividade do emprego desse meio na sociedade, destacando-se sua incidência após a vigência do Código de Processo Civil de 2015.

Para tanto e tendo em vista essa problematização e objetivo, observando essa metódica exploratória descritiva e jurídico-projetivo, dentro do campo dedutivo, sistêmico e axiológico, utilizou-se a revisão bibliográfica sobre a temática central proposta, bem como a análise de dados coletados por órgãos oficiais e da legislação brasileira, além de decisão de Tribunal Superior que estabeleceu precedente judicial importante sobre o tema.

Tudo com o fim de fazer uma análise do sistema judiciário brasileiro, tendo em vista a extrajudicialização como um meio condizente de solução de conflitos com a realidade social atualmente.

\section{Resultados e Discussão}

\subsection{O fenômeno da desjudicialização ou extrajudicialização dos procedimentos}

Em primeiro lugar, é necessário que se entenda o acesso à justiça, porquanto se pressupõe que esta seja efetiva, adequada, eficiente e justa, o que é de fundamental importância para se assegurar a defesa dos direitos intrínsecos da sociedade (Marchetti Filho, 2018).

Tal é sua relevância que, à medida que a sociedade se transforma, essa diretriz conceitual evolui, "talvez na mesma proporção que a sociedade cresceu, maximizou-se e transformou-se ao longo dos tempos, com reflexos no direito e na sua necessidade de atender aos anseios dessa sociedade em constante evolução e transformação” (Marchetti Filho, 2018, p. 169).

Em consequência disso "o conceito de acesso à justiça sempre se vinculou ao direito de ingressar ou de contestar uma ação diante de um direito lesionado" (Marchetti Filho, 2018, p. 169). Porém, com o progresso da sociedade e dos conflitos sociais, o Poder Judiciário brasileiro vem se apresentando inadequado para aplicar determinadas medidas que assegurem o direito demandado e ofereça a segurança que a decisão jurisdicional será aplicada como é previsto.

Nesse contexto atual de sobrecarga do Judiciário, “o Estado deve oferecer alternativa viável para a manutenção da paz social mediante instrumentos de prevenção e de solução de conflitos” (Araújo, 2016, p. 59). Essa é a razão pela qual "não podemos discordar da doutrina que denomina o processo como utlima ratio (último recurso disponível), [...] no sentido de que 
uma sociedade organizada somente deve resolver os conflitos individuais ou coletivos perante regras preestabelecidas" (Araújo, 2016, p. 59), seja por meio do processo, seja por meio de outras formas adequadas de solução.

Trilhando nisso, "atualmente o sistema incentiva e propaga os meios alternativos de solução de conflitos, para os quais não há obrigatoriedade da participação do juiz como representando do Estado" (Araújo, 2016, p. 59), destacando-se, entre elas, a conciliação, mediação e arbitragem.

Seja como for, o fato é que, diante do cenário em que se encontra o Judiciário, a lei precisa e deve adotar instrumentos alternativos, adequados a possibilitar que todos tenham acesso facilitado à justiça com o fim de ter seu direito tutelado, visto que "o consumidor de serviço judiciário deve recebê-lo de forma adequada, pronta e eficiente" (Gonçalves, 2019, p. 45).

Tendo em vista essa ideia, o Código de Processo Civil traz em seu ideário o implemento e incentivo de outros meios adequados de solução de conflitos, no sentido de que, pelo seu art. $3^{\circ}, \S 2^{\circ}$, "o Estado promoverá, sempre que possível, a solução consensual dos conflitos" (Lei Federal n. 13.105, 2015).

É nesse contexto de meios adequados a solução de conflitos que se ingressa a desjudicialização ou extrajudicialização, um mecanismo alternativo de solução de conflitos e pacificação social que tem como objetivo dar maior efetividade e celeridade ao procedimento, realizando-o fora da esfera judicial.

No panorama apresentado, os atos extrajudiciais passam a ser "grandes aliados da solução consensual dos conflitos e da pacificação social. Estão associados à noção de 'desjudicialização', ou seja, da possibilidade de resolver questões jurídicas fora do âmbito das ações judiciais" (Pinto, 2019).

É um avanço que promove o acesso à justiça de forma descomplicada e dinâmica, afastando o monopólio do Judiciário devido à singeleza de determinados procedimentos, tendo como norte a Constituição Federal e o próprio Código de Processo Civil.

Trata-se de um caminho utilizado por quem busca não se submeter a morosidade do Poder Judiciário, uma vez que este acumula um número cada vez maior de ações devido ao excesso de demandas já existentes e as que são postuladas diariamente, fato que se dá pela cultura do litígio, tanto da parte do Judiciário quanto da sociedade.

Exemplo disso está na usucapião e a possibilidade de seu processamento diretamente no cartório extrajudicial, conforme instituído pelo próprio Código de Processo Civil, em 2015, conforme seu art. 1.017, que inseriu o art. 216-A na Lei de Registros Públicos (Lei Federal n. 6.015/1973), pelo qual “sem prejuízo da via jurisdicional, é admitido o pedido de reconhecimento extrajudicial de usucapião, que será processado diretamente perante o cartório do registro de imóveis da comarca em que estiver situado o imóvel usucapiendo" (Brasil, 1973).

Nota-se que "a modificação introduzida é importante, e corresponde à tendencia de desjudicialização de procedimentos, que podem atingir seu fim sem a necessidade de participação do Poder Judiciário” (Araújo, 2018, p. 56).

Tudo isso retrata a materialização do direito fundamental e princípio processual da duração razoável do processo, pelo qual se tem que "a demora na solução dos conflitos traz ônus gravosos àquele que ingressa em juízo, o que estimula o adversário a tentar prolongar indefinidamente o processo. Devem-se buscar mecanismos que repartam esses ônus" (Pinto, 2019).

Nesses termos, a desjudicialização "decorrente do constante esforço no sentido de desafogar as serventias judiciais da exacerbada quantidade de demandas postas ao exercício da jurisdição, movimento que ganhou fôlego desde a Emenda Constitucional n. 45/2004" (Barroso et al., 2017, p. 198).

Aliás, por essa Emenda, foi agregado o inciso LXXVIII ao art. $5^{\circ}$ da Constituição Federal. Por ele, "a todos, no âmbito judicial e administrativo, são assegurados a razoável duração do processo e os meios que garantam a celeridade de sua tramitação" (1988). Trata-se da constitucionalização do princípio da duração razoável do processo. E pelo art. $4^{\circ}$ do Código de Processo Civil, "as partes têm direito de obter em prazo razoável a solução integral do mérito, incluída a atividade satisfativa" 
(Brasil, 2015).

Observa-se que a "desjudicialização aponta a transferência facultativa de algumas atividades que, até então, eram atribuições específicas do Poder Judiciário, para o âmbito das serventias extrajudiciais, admitindo que estes órgãos possam solucionar o conflito por meio de procedimentos administrativos" (Marchetti Filho et. al, 2020).

Desse modo, as vantagens que permeiam a escolha pela via extrajudicial são positivas, a título de exemplo tem-se a economia de tempo, o acesso mais efetivo à justiça, sem sobrecarregar os serviços jurisdicionais do Estado, além da evidente redução de custos de processamento, tanto para as partes interessadas como para o Estado, pois "de nada adianta uma solução de conflito efetiva e justa, mas que chega até as partes tardiamente ou desprovida de qualidade" (Marchetti Filho, 2018, p. 182).

Há precedentes legislativos de extrema relevância acerca da extrajudicialização, como a retificação extrajudicial de registro imobiliário (Lei Federal n. 10.931/04), o divórcio e o inventário extrajudicial introduzidos por força Lei Federal n. 11.441/07), a consignação em pagamento extrajudicial (arts. 539 e seguintes do Código de Processo Civil de 2015), a conciliação em serventias extrajudiciais (Provimento n. 12/2013), entre outros.

À título de exemplo, no campo específico da usucapião, o Código de Processo Civil não mudou "o panorama na hipótese de o processo de usucapião perfazer-se em juízo, malgrado tenha suprimido algumas etapas antes necessárias. Mas abre a possibilidade do manejo pela via extrajudicial, certamente para evitar a complexidade e delonga da judicialidade" (Marquesi, 2018, p. 51).

Em vista disso, é evidente que os métodos de solução de conflitos extrajudiciais favorecem a celeridade, a segurança jurídica e a redução de custos de processamento. Portanto, é necessário que se aplique técnicas para uniformizar e adequar os procedimentos que fazem jus à extrajudicialização. Mas, embora tenha se avançado muito em relação a desjudicialização do direito, alguns instrumentos ainda permanecem inadequados e limitados.

\subsection{Necessidade de adequação dos meios de solução de conflito para a pacificação social}

O homem, na sua trajetória evolutiva, tem premência básica de conviver em sociedade. É um aspecto natural da essência humana ser e estar inserido em um determinado grupo social, pois o ser humano possui relação de interdependência com o outro.

Desse modo, trata-se de "um ser de relações sociais, na qual traz para si normas, valores vigentes na família, em seus pares e na sociedade" (Tartuce, 2018, p. 20), pois está inserido em uma sociedade hiperdinâmica que cresce a cada dia.

Nesse contexto, "a ocorrência de conflitos tende a se incrementar em virtude da dinâmica das relações interpessoais, cuja variação é intensa nos tempos recentes” (Tartuce, 2018).

Alinhado nesse raciocínio, o ser humano naturalmente envolve-se em conflitos de interesse, uma vez que, desde seu nascimento, o homem é absorvido por relações interpessoais na sociedade, nascendo de tais relações os conflitos de interesses.

Desses conflitos sociais surge a necessidade do Estado, na posição de guardião da pacificação social, editar normas especificando quais são os limites dos direitos e deveres de cada um. Porém, à medida que a sociedade se transforma, os conflitos de interesse crescem proporcionalmente e, com o passar do tempo, se tornam mais complexos (Marchetti Filho et. al, 2020).

Nessa trilha, torna-se necessário arquitetar um sistema capaz e eficiente para lidar com controvérsias que aparecem, "especialmente diante da busca de uma abordagem adequada e eficiente do complexo fenômeno conflituoso, revela-se essencial a contribuição de olhares diversos e complementares em relação ao aspecto jurídico" (Tartuce, 2018, p. 25).

Nesse norte, "a lei atribui numerosos direitos aos membros da coletividade" (Gonçalves, 2019, p. 39). Com isso, pressupõe-se que o detentor de um direito compreenda que, caso este não tenha sido respeitado, há a possibilidade de que 
recorra aos serviços jurisdicionais para obter a garantia desse direito.

Assim, a própria sociedade e a coletividade inserida nos sistemas sociais ferem os direitos uns dos outros, e, com isso, as normas editadas pelo legislador como regras de conduta são violadas. É nessa situação que o conflito de interesse, como um fenômeno sociológico, se torna objeto de uma relação processual.

Consequentemente, em decorrência da previsão legal de que quem tem seu direito lesado tem o direito de postulá-lo perante o Judiciário, criou-se a cultura do litígio, pela qual a coletividade não busca formas de solucionar o conflito consensualmente, motivo pelo qual o sistema Judiciário se afoga em um número absurdamente grande de demandas sem solução ou sentença.

Seguindo o entendimento, "quando se fala em escopo social do sistema processual, tem-se a sua análise mediante a função da jurisdição e do processo dentro da sociedade, à vista da resolução de conflitos e tutela adequada do direito" (Marchetti Filho, 2018, p. 202).

Nesse tocante, de acordo com o relatório Justiça em Números do Conselho Nacional de Justiça, “o Poder Judiciário finalizou o ano de 2018 com 78,7 milhões de processos em tramitação, aguardando alguma solução definitiva. Desses, 14,1 milhões $(17,9 \%)$ estavam suspensos, sobrestados ou em arquivo provisório, aguardando alguma situação jurídica futura. Dessa forma, desconsiderados tais processos, tem-se que, em andamento, ao final do ano de 2018 existiam 64,6 milhões ações judiciais" (Conselho Nacional de Justiça, 2019, p. 79).

Ainda de acordo com o Conselho, "em média, a cada 100.00 mil habitantes, 11.796 ingressaram com uma ação judicial no ano de 2018" (Conselho Nacional de Justiça, 2019, p. 80). O relatório demonstra que "durante o ano de 2018, foram proferidas 32 milhões de sentenças e decisões terminativas, com aumento de 939 mil casos (3\%) em relação à 2017. Registrase, também, crescimento acumulado de 36,8\% da produtividade em 10 anos” (Conselho Nacional de Justiça, 2019, p. 80).

Diante desses dados, “o que se pode verificar ao longo desse processo, é que o Judiciário não tem contribuído de forma efetiva, com justiça e eficiência no que concerne à resolução das lides, restando prejudicada exatamente essa ideia da pacificação do conflito" (Marchetti Filho et. al, 2020, p. 36).

Observa-se, assim, que a sociedade brasileira é dependente da solução processual do conflito e, dessa maneira, contribui para um estoque cada vez maior de ações e, consequentemente, promovendo dificuldades na administração e na tramitação processual no Judiciário.

Consequentemente, o sistema Judiciário vem se tornando cada vez mais inadequado para aplicar medidas que assegurem o direito do indivíduo e ofereça a segurança da legitimidade da decisão jurisdicional, e que esta será aplicada como é esperado. Isso porque "um dos problemas do processo tradicional é a multiplicidade de formas e solenidades, que redunda na morosidade do processo" (Gonçalves, 2019, p. 720).

O excesso de demandas que tramitam no Poder Judiciário é apontado como a principal causa da sua morosidade, motivo que se dá pela abundância de casos que poderiam ser resolvidos fora dos tribunais.

À título de exemplo, tem-se o divórcio consensual, regulamentado pela Lei Federal n. 11.441/2007, que possibilita às partes interessadas se dirigirem diretamente ao Cartório Extrajudicial e realizar o requerimento de dissolução do casamento de forma amigável.

Isso é consequência da insegurança que a sociedade tem nesse meio de solução de conflito, bem como na facilidade que se tem de modificar normas. Como o alicerce da ordem jurídica são as normas, sendo elas modificadas continuamente pelo Poder Legislativo, os cidadãos optam por recorrer aos serviços do Judiciário em busca de segurança.

Em oposição a isso, devido ao estado em que a estrutura do Poder Judiciário se encontra, ele não está apto a oferecer segurança ao titular do direito, visto que, ao solucionar o conflito por meio de uma sentença em determinado caso concreto, essa decisão pode vir tardiamente, quando a solução já não interessa mais ou perdeu seu sentido. 
Disso decorre a necessidade de se adequar os meios para solução de conflitos e promover a pacificação social de acordo com as mudanças estruturais que a sociedade contemporânea vem sofrendo. Nesse passo,

a obrigatoriedade de submissão a meios consensuais e as motivações do seu prestígio no âmbito do Poder Judiciário podem ser questionadas: a adoção de uma tônica impositiva e quantitativa em prejuízo da qualidade da abordagem dos conflitos pode comprometer sua adequação e sua legitimidade. No entanto, ainda que se considere o elemento quantitativo incentivador, é inegável a mudança de visão verificada nos últimos anos: como o processo judicial não mais vem sendo considerado via adequada para compor todos os conflitos, deve o Estado oferecer meios diversos para garantir o acesso à justiça. (Tartuce, 2018, p. 27)

Portanto, o objetivo do movimento de adequação é "facilitar o acesso à justiça, tornando consumidores dela pessoas que possivelmente não levariam a juízo seus litígios de menor extensão" (Gonçalves, 2019, p. 44), pois, na atualidade, há priorização por pontos do processo relacionados ao acesso à justiça, bem como a celeridade procedimental, economia de tempo e minimização dos custos.

Seguindo essa linha de raciocínio, tem-se que o Código de Processo Civil de 2015 tem como mote "uma valoração do consenso e uma preocupação em criar no âmbito do Judiciário um espaço não apenas de julgamento, mas de solução de conflitos', tendo em vista a pacificação” (Marchetti Filho, 2018, p. 213).

E, trilhando nesse pensamento, "inaugura-se com a vigência do atual Código de Processo Civil a tendência de meios adequados para as soluções de conflito. A sua pacificação deve ser incentivada pelos operadores do direito, para que a cada dia seja mais aplicada caso a caso, dentro da ideia de solução adequada de conflitos" (Marchetti Filho et. al, 2020).

Nesse contexto, sobreleva observar que se deve "atentar para a possível oferta de mecanismos diferenciados para compor conflitos de índole eminentemente privada, de forma que os próprios envolvidos no impasse possam localizar meios para reorganizar suas situações e, desejando, construir saídas consensuais” (Tartuce, 2018, p. 26).

A extrajudicialização entra nesse contexto como um bálsamo para quem procura a tutela de seus direitos sem se submeter à morosidade do sistema judiciário. Na prática, hoje temos a previsão legal de vários procedimentos desjudicializados ou extrajudiciais, dos quais podemos citar a venda extrajudicial da coisa imóvel objeto de alienação fiduciária com inadimplemento do devedor, a retificação de registro civil, a realização de inventário, partilha, separação e divórcio consensual, a conversão em propriedade do título de legitimação de posse no âmbito do Programa Minha Casa, Minha vida, o inventário extrajudicial e a usucapião (Barroso et al., 2017).

Uma dessas “inovações” surgiu por força da Lei Federal n. 11.441/2007, possibilitou o divórcio e separação consensual, assim como o inventário extrajudicial. Outra importante mudança adveio com o Código de Processo Civil de 2015 que trouxe certas inovações no que diz respeito aos meios adequados de solução e pacificação de conflitos e, dentre elas, a possibilidade da usucapião extrajudicial.

São pontos positivos relativos à escolha da via extrajudicial a economia de tempo, bem como melhor acesso à justiça, pois a escolha pela via extrajudicial evita que vários conflitos de solução simples cheguem ao Judiciário desnecessariamente, eis que podem ser resolvidas sem o crivo processual, e é nesse ponto que se encontra a efetividade na abordagem do conflito e a facilitação do acesso à justiça.

Contudo, a simples disposição da lei "não altera uma tradição tão larga de judicialização nem modifica uma cultura de obediência e formalidade dos serviços notariais ou registrais” (Guedes et al., 2019).

Vislumbra-se então que, "para além de uma sistematização dos meios consensuais, é preciso também uma política pública efetiva de conscientização social que busque a mudança de paradigma, para se ter o fim da cultura de litigiosidade e a implementação da cultura da pacificação social” (Marchetti Filho, 2018, p. 245).

É preciso, assim, dar um passo a mais para prover a adequação de tais procedimentos, ambicionando disciplinar a 
aplicação de normas legais pelos cartórios registrais e notariais, uma vez que somente dispor sobre tais procedimentos não modifica o pensamento de que tudo concernente a leis deve ser judicializado.

\subsection{Vantagens da via extrajudicial como na solução de conflitos}

O acesso à justiça é, de fato, tema complexo e de suma relevância a ser estudado, pois é direito de todos os cidadãos o acesso à recursos capazes de proteger direitos legalmente previsto, tanto na Constituição Federal, como no ordenamento jurídico em geral.

O acesso à justiça não engloba apenas a possibilidade do sujeito de postular em juízo ou a admissão do processo. Envolve, também, o amparo que o Estado deve oferecer de forma efetiva e desempenhar seu papel com eficiência a oferecer a consecução do direito demandado.

Diante disso, Marchetti Filho (2018, p. 175) esclarece que "o acesso à justiça dentro da ideia da humanização e democratização do direito como um todo, mas principalmente o processual, ganha contornos muito mais significativos do que apenas a garantia de se bater às portas do Judiciário e de se ter uma sentença de mérito que "põe fim ao conflito"”.

Por este motivo, as transformações que ocorrem na esfera processual estão intrinsecamente vinculadas a função jurisdicional, qual seja, promover a pacificação social dos conflitos de interesse de modo efetivo, do momento em que recebe as demandas da massa a ocasião de aplicar a decisão ao caso concreto resolvendo o litígio, visando a eficácia e a produção de resultados justos.

Ao passo que o sistema de julgamento do Poder Judiciário se tornou inadequado para regular conflitos por não ter condições de propiciar uma sentença justa e célere, ensejou-se a busca por meios adequados para solucionar tais relações e propiciar ao cidadão o acesso à justiça de forma organizada e apropriada, comprometida a tutelar o direito garantido ao indivíduo.

Insere-se, então, nessa busca por desjudicialização do direito, os Cartórios e Serventias Notariais e Registrais que tem por princípio garantir a publicidade, eficácia e segurança dos atos jurídicos.

O sistema extrajudicial dos cartórios e serventias tem por objetivo dar ao procedimento maior simplicidade, porquanto, desse modo, o procedimento contará com economia de tempo e recursos financeiros, resultando em maior celeridade, o que beneficiará os interessados.

Nessa trilha, "apesar de ser exercida em caráter privado, a Atividade Registral exerce uma Função Pública, de garantia da segurança jurídica dos atos praticados pelos Registradores" (Azevedo, 2015, p. 59).

Seguindo essa linha de raciocínio, tem-se uma gama ampla de atos que podem ser realizados perante os Cartórios, desde que preenchidos determinados requisitos referentes a cada procedimento. Desse modo, o Código de Processo Civil, Lei Federal n. 13.105, aprovada em 16 de março de 2015, implantou dispositivos que influenciam as atividades realizadas pelos cartórios registrais e notariais.

A lei sancionada, ao implantar novos dispositivos versando sobre atividades extrajudiciais, contribuiu para que procedimentos, antes judicializados, pudessem ser resolvidos pela via extrajudicial, como é o caso do Usucapião Extrajudicial, regulado pela Lei n. 6.015/1973 (Lei de Registros Públicos), no art. 216-A, com redação dada pelo Código de Processo Civil de 2015 e pela Lei Federal n. 13.465/2017, além de especificado pelo Provimento n. 65 do Conselho Nacional de Justiça.

É indiscutível que esse dispositivo amparou os processos de usucapião que ficavam estagnados devido à obstáculos enfrentados tanto pela parte interessada quanto para o órgão recorrido, como o problema fundamental, qual seja, saber da localização dos proprietários dos imóveis usucapidos, uma vez que a maioria dos posseiros desconhecem dos donos.

No sistema brasileiro, o Registro de Títulos e Documentos de qualquer espécie, que seja apto ao registro, tem a essencial finalidade de garantir a publicidade dos atos, de modo a ser oponível erga omnes após seu registo, dar autenticidade e 
segurança jurídica aos atos praticados, bem como proporcionar eficácia do procedimento.

Tais documentos oferecem garantias jurídicas aos indivíduos, pois são revestidos de fé pública, garantem a perpetuidade do documento registrados, bem como todos os cumprimentos das exigências legais, fiscais e de arrecadação dos tributos devidos (Azevedo, 2015).

\subsection{As possibilidades ligadas à via extrajudicial}

A busca por meios que colaborem para a simplificação do processo é constante, assim como a mutação da sociedade e dos conflitos sociais nela inseridos, e as novas contendas que se originam com o passar o tempo.

Para que o que o cidadão recorra aos serviços cartorários, é necessário que haja a adequação destes procedimentos e, fundamentalmente, de forma expressa, a regulamentação das possibilidades que são compatíveis com a atividade registral.

Desse modo, verifica-se existir uma ampla rede de possibilidades ligadas à mecanismos a serem empregados em prol da pacificação dos conflitos sociais, estimulando a desjudicialização. Tal ideia se vincula perfeitamente a atuação das serventias extrajudiciais, que devem ser referência não apenas como base para dar publicidade a atos negociais e registrais, dentre outras relações e atos jurídicos, mas também como meio para a solução eficiente e adequada de conflitos.

Ilustra perfeitamente o êxito da iniciativa de extrajudicialização a Lei Federal n. 11.441/2007, que possibilitou a realização de Inventários e Divórcios Consensuais por meio dos Cartórios.

Nessa toada, a 4 $4^{\text {a }}$ Turma do Superior Tribunal de Justiça, pelo Recurso Especial n. 1.808.767 (Brasil, 2019), abriu importante precedente em relação ao inventário extrajudicial, ao decidir pela possibilidade de inventário extrajudicial mesmo quando o de cujus tenha deixado testamento, desde que os interessados sejam maiores, capazes e concordes, e estejam acompanhados de seus respectivos advogados. Nesse sentido, a ementa da decisão consigna:

1. Segundo o art. 610 do CPC/2015 (art. 982 do CPC/73), em havendo testamento ou interessado incapaz, procederse-á ao inventário judicial. Em exceção ao caput, o $§ 1^{\circ}$ estabelece, sem restrição, que, se todos os interessados forem capazes e concordes, o inventário e a partilha poderão ser feitos por escritura pública, a qual constituirá documento hábil para qualquer ato de registro, bem como para levantamento de importância depositada em instituições financeiras.

2. O Código Civil, por sua vez, autoriza expressamente, independentemente da existência de testamento, que, "se os herdeiros forem capazes, poderão fazer partilha amigável, por escritura pública, termo nos autos do inventário, ou escrito particular, homologado pelo juiz" (art. 2.015). Por outro lado, determina que "será sempre judicial a partilha, se os herdeiros divergirem, assim como se algum deles for incapaz" (art. 2.016) - bastará, nesses casos, a homologação judicial posterior do acordado, nos termos do art. 659 do CPC.

3. Assim, de uma leitura sistemática do caput e do $\S 1^{\circ}$ do art. 610 do CPC/2015, c/c os arts. 2.015 e 2.016 do CC/2002, mostra-se possível o inventário extrajudicial, ainda que exista testamento, se os interessados forem capazes e concordes e estiverem assistidos por advogado, desde que o testamento tenha sido previamente registrado judicialmente ou haja a expressa autorização do juízo competente.

4. A mens legis que autorizou o inventário extrajudicial foi justamente a de desafogar o Judiciário, afastando a via judicial de processos nos quais não se necessita da chancela judicial, assegurando solução mais célere e efetiva em relação ao interesse das partes. Deveras, o processo deve ser um meio, e não um entrave, para a realização do direito. Se a via judicial é prescindível, não há razoabilidade em proibir, na ausência de conflito de interesses, que herdeiros, maiores e capazes, socorram-se da via administrativa para dar efetividade a um testamento já tido como válido pela Justiça. (Brasil, 2019)

Trata-se de julgado que resulta tanto da busca pela celeridade processual, quanto da efetividade, ambos propiciados pelo meio extrajudicial de solução de conflitos, com o fim de evitar que mais ações se acumulem no sistema judiciário contribuindo para a morosidade do procedimento.

Tal precedente foi relatado pelo ministro Luis Felipe Salomão (Brasil, 2019), e teve acompanhamento unânime dos votos da referida turma. A ação teve origem no Tribunal de Justiça do Rio de Janeiro, que, por unanimidade, decidiu sobre a 
impossibilidade do feito sob o fundamento do art. 610 do Código de Processo Civil de 2015 que determina a abertura do inventário judicial quando houver testamento, priorizando a última vontade do de cujus.

Ao proclamar seu voto, o relator firmou que o inventário extrajudicial busca exatamente desafogar o Poder Judiciário, ao possibilitar uma outra via para solução da distribuição dos bens entre os herdeiros, sem necessidade de intervenção judicial pelo processo, assegurando, assim, uma solução da problemática da partilha de bens após a morte de maneira mais efetiva, justa, eficaz e adequada em relação ao interesse das partes (Brasil, 2019).

Dessa forma, observa-se que esta decisão abriu caminho para dar solução mais célere a procedimentos que tramitam anos e anos no sistema judiciário, e podem perder a eficácia da decisão em consequência da delonga processual.

Esse precedente vem sendo recepcionado de maneira positiva pela doutrina e jurisprudência, de maneira a incentivar a partilha amigável feita pelas serventias extrajudiciais, além de contribuir para o andamento da justiça, representando ganho de tempo e redução de custos (Consultor Jurídico, 2019).

Consoante a isso, observa-se que tal precedente contribui para conferir segurança jurídica aos atos praticados pelas serventias extrajudiciais e corrobora com o art. $5^{\text {ol }}$ da Lei de Introdução às Normas do Direito Brasileiro, bem como os artigos $3^{\circ}, 4^{\circ}$ e $8^{\circ 2}$ do Código de Processo Civil, ao deixar implícito que, na busca pelos meios adequados de solução de conflito, as finalidades da via extrajudicial são reduzir a burocracia inerente da judicialização e os instrumentos de formalidade que tanto delongam o processo, com o acréscimo de procedimentos e solução de controvérsias por meios alternativos (Consultor Jurídico, 2019).

Como dito, o grande marco foi a Lei Federal n. 11.441/2007, que autorizou o divórcio e separação consensual. "Se não houver bens a partilhar, um divórcio pode ser resolvido até no mesmo dia, caso as partes apresentem todos os documentos necessários para a prática do ato e estejam assessoradas por um advogado" (Dino, 2018).

Mas, a despeito de todas as possibilidades e evoluções que poderiam ocorrer, de lá para cá pouco se alterou. Aliás, o Código de Processo Civil somente modificou "a redação do inventário e partilha extrajudiciais previstas no Código de Processo Civil de 1973 e deixou à deriva questões como a possibilidade de, mesmo havendo testamento válido, se recorrer às vias extrajudiciais" (Riva et al., 2020, p. 2003).

Diante disso, como destacam Riva e Guimarães (2020, p. 2003), "os maiores avanços, ainda, ficam a cargo da possibilidade de os Cartórios servirem de instrumento para a desjudicialização do processo, ou seja, de não se levar a juízo alguns procedimentos de jurisdição voluntária".

Ademais, a própria "conciliação pode ser obtida e ter caráter resolutivo por três caminhos: no processo originalmente contencioso, quando se tornam concordes as partes, quando são concordes e levam à homologação judicial ou quando são concordes e fazem a resolução sem intervenção judicial, por escritura pública e posterior registro" (Guedes et al., 2019).

Ainda de competência dos cartórios, a Lei Federal n. 6.766/79, possibilitou o depósito, de Registros de Imóveis, de prestações concernente a aquisição de lotes, onde o adquirente faz o depósito das prestações e da ciência da aquisição mediante o Registro Imobiliário.

Já a Lei n. 8.560/92 instituiu importante alternativa para o reconhecimento voluntário do vínculo de paternidade, sem

\footnotetext{
${ }^{1}$ Art. $5^{\circ} \mathrm{Na}$ aplicação da lei, o juiz atenderá aos fins sociais a que ela se dirige e às exigências do bem comum.

${ }^{2}$ Art. $3^{\circ}$ Não se excluirá da apreciação jurisdicional ameaça ou lesão a direito.

$\S 1^{\circ}$ É permitida a arbitragem, na forma da lei.

$\S 2^{\circ}$ O Estado promoverá, sempre que possível, a solução consensual dos conflitos.

$\S 3^{\circ}$ A conciliação, a mediação e outros métodos de solução consensual de conflitos deverão ser estimulados por juízes, advogados, defensores públicos e membros do Ministério Público, inclusive no curso do processo judicial.

Art. $4^{\circ}$ As partes têm o direito de obter em prazo razoável a solução integral do mérito, incluída a atividade satisfativa.

[...]

Art. $8^{\circ}$ Ao aplicar o ordenamento jurídico, o juiz atenderá aos fins sociais e às exigências do bem comum, resguardando e promovendo a dignidade da pessoa humana e observando a proporcionalidade, a razoabilidade, a legalidade, a publicidade e a eficiência. (Brasil, 1942)
} 
a necessidade de ação própria para isso, bastando a declaração da pessoa no sentido de se reconhecer a paternidade.

Por sua vez, a Lei Federal n. 9.514/97, que foi um marco na época de sua promulgação, instituiu a alienação fiduciária de bens imóveis, estendendo a propriedade fiduciária aos imóveis, que é forma de garantia o débito e tem maior praticidade no recebimento do crédito em caso de inadimplência, sendo mais célere, econômica e segura.

Difere da hipoteca, pois esta necessariamente depende de um processo judicial de execução; e a propriedade fiduciária permite realizar a alienação do bem extrajudicialmente, sem a necessidade de um processo de execução.

Em 2004, modificando o art. 213 da Lei Federal n. 6.015/73, a Lei n. 10.931 autorizou a retificação e averbação administrativa relativa ao registro de imóveis, destacando a desnecessidade de tutela judiciária.

Merece destaque, ainda, o art. 1.071 do Código de Processo Civil de 2015, que inseriu o art. 216-A na Lei no 6.015, instituindo a possibilidade de declaração de usucapião pela via extrajudicial.

Há, também, a possibilidade elencada no art. 571 do Código de Processo Civil, da realização de demarcação e divisão pela via extrajudicial, por meio de escritura pública, respeitados os requisitos legais.

Em vista disso, é enfática a segurança jurídica que os atos registrais e notariais garantem aos procedimentos tanto quanto os realizados na via Judiciária, pois é "a segurança jurídica que traz estabilidade às relações sociais juridicamente tuteláveis [...], dá amparo às relações entre as pessoas e o Estado e entre as pessoas entre si” (Azevedo, 2015, p. 202).

Assim sendo, a credibilidade da solução jurídica da crise conflituosa oferecida pela via extrajudicial é, hoje, notória, pois "surtindo os efeitos que lhe são atribuídos, imprimem ao ato uma existência legal e autêntica" (Azevedo, 2015, p. 349).

Desse modo, a extrajudicialização dos procedimentos que abriu espaço para a desjudicialização dos instrumentos processuais, é importante mecanismo no que diz respeito a evolução dos meios de pacificação social, necessitando ter um estímulo mais amplo por parte do próprio Poder Judiciário e do Conselho Nacional de Justiça, por meio de implementação de políticas públicas de conscientização da sociedade, de modo a consolidá-la e efetivá-la como um indispensável elemento do sistema jurídico.

Nessa toada, dentre os vários benefícios propostos pela via administrativa, destaca-se o alívio de carga do Poder Judiciário, pois proporciona um caminho para a composição de conflitos sem que as partes tenham que recorrer a tutela jurisdicional, contribuindo para que o desvio produtivo do Judiciário diminua com o aumento da busca pela via extrajudicial.

\subsection{O custo de processamento no cartório extrajudicial como obstáculo para sua efetividade}

Como se sabe, as despesas pagas pela realização de um serviço em cartório são chamadas de emolumentos. Seu valor é definido por uma tabela de custas, que é instituída por Lei Estadual, de modo que cada Estado possui poder e autonomia para estabelecer as taxas a serem cobradas.

Desse modo, o poder delegado aos Estados gera certa insegurança e caracterizam um obstáculo para a extrajudicialização porque, apesar dos serviços realizados serem exatamente os mesmos em todo território brasileiro, os valores possuem distinções em cada Estado, pois incidem sobre eles uma abundância de encargos financeiros.

Veja-se que, apesar da desburocratização ser uma característica dos procedimentos extrajudiciais, esse ponto em desfavor contribui para que a adequação do procedimento não se dê de forma uniforme em todos os Estados brasileiros.

Outro ponto a ser destacado é que, mesmo após a entrada em vigor do Código de Processo Civil de 2015, não há a previsão de gratuidade de escritura pública para aqueles que declaravam pobreza.

Desse modo, "há certa contradição entre essa retirada da norma em benefício aos pobres e o espírito da nova codificação processual, que adota a agilização e a desjudicialização como motes principiológicos" (Tartuce, 2015, p. 345).

No Mato Grosso do Sul, a Lei Estadual n. 3.003, de 2005, fixa o valor de emolumentos devidos pelos atos praticados pelos serviços notariais e de registro no Estado. Por ela, as custas para registro integral de título, contrato ou documento com 
valor econômico varia de $\mathrm{R} \$ 131,00$ a $\mathrm{R} \$ 7.847,00^{3}$, de acordo com o valor avaliado pela AGENFA do Estado no caso de inventário. E, em se tratando de divórcio, as custas dependem do valor total do patrimônio e regime de bens.

De acordo com a Lei Estadual, o preço do ato é calculado com base nos valores tributários do Munícipio ou de competência do Estado, ou seja, mesmo dentro da esfera estatal pode ocorrer a variação de valores, visto que pode se utilizar critérios de valoração para cálculo de impostos municipais, como o ITBI.

Para o Registro de Incorporação de Imóveis, de acordo com a referida Lei, que garante ao comprador que o condomínio será entregue respeitando os métodos e prazos legais, a distinção de preço é maior ainda, variando de $\mathrm{R} \$ 770,00$ a $\mathrm{R} \$ 24.575,00$, dependendo do valor do ato.

Como consequência de taxas altíssimas, o proprietário do imóvel deixa de registrá-lo no Cartório pertinente, sofrendo, assim, a insegurança jurídica que provém de tal fato e o Munícipio deixa de arrecadar o imposto que seria aplicado em melhorias em prol da população.

Com efeito, a parte interessada acaba por não recorrer aos serviços das serventias extrajudiciais, e isso mostra a inefetividade concreta da via extrajudicial exatamente pelos custos elevados e oscilantes dos serviços, afetando a produtividade local, criando um movimento de dispersão para outros Estados, na demanda por serviços com preços mais baixos.

Ao se realizar um procedimento em cartório, o percentual de tributos que são repassados, além dos valores cobrados no cartório, varia de $4 \%$ a $32,5 \%$, a serem pagos por quem requereu o ato a ser registrado pelo notário ou registrador.

A composição de valores a serem repassados oscilam de um ente e outro. Para o Tribunal de Justiça do Mato Grosso do Sul, o valor consta de $10 \%$ acrescidos de 5\% de ISSQN, conforme a lei de cada Município; para Ministério Público Estadual o valor repassado é de 10\%; para a Defensoria Pública 6\%; e a Procuradoria-Geral do Estado recebe o valor de 4\% (ANOREG, 2018).

Ao cartório é recolhida a taxa de 32,5\% dos valores pagos, ao passo que, ao Governo do Estado, é repassada a taxa de 27,5\% do valor disposto no cartório, que faz frente aos custos da serventia que se constituirá em receita pública. Além de tais valores, é repassado ao Poder Judiciário (FUNJECC) a taxa de 15\%, fixada de acordo com o art. 236 da Constituição Federal ${ }^{4}$ e com a tabela de emolumentos do Estado (ANOREG, 2018).

Tais repasses acabam sobrecarregando o custo do serviço a ser realizado. Em decorrência disso, o serviço prestado se mostra ineficaz ao cidadão, pois gera custas maiores que o esperado, afetando a produtividade do Estado, gerando desperdício de tempo e, para o cidadão contribuinte, a disposição de tais verbas que afetam e dificultam sua escolha no momento de recorrer a tutela do ente para tutelar seu direito.

Este é o quadro em que se encontra as serventias extrajudiciais. Altamente eficaz no que tange a celeridade de procedimentos, porém não é dada a devida importância no que diz respeito aos custos de processamento, que deve se adequar e uniformizar a discrepância de valores que prejudica o cidadão.

Os altos valores acabam por afastar as pessoas da via extrajudicial, que tem como principal função garantir a eficácia e segurança jurídica do procedimento, eivado de tantos princípios que amparam o direito do cidadão.

Importante mencionar que, "por tal razão, pode-se revelar mais interessante a abordagem consensual do que a inerente

\footnotetext{
${ }^{3}$ Lei 3.003/2005. Art. $1^{\circ}$ Esta Lei estabelece os emolumentos devidos pelos atos praticados por notários e registradores e disciplina os casos de isenção e não incidência, a forma de pagamento, a fiscalização e as penalidades para o descumprimento dos preceitos estabelecidos.

Parágrafo único. Consideram-se emolumentos os valores devidos a título de remuneração pela prestação de serviços públicos notariais e de registro previstos na Lei n. 8.935/1994.

Art. $2^{\circ}$ São contribuintes dos emolumentos as pessoas físicas ou jurídicas que utilizam os serviços públicos prestados por notários e registradores.

Art. $3^{\circ}$ São sujeitos passivos, por substituição, no que se refere aos emolumentos, os notários e os registradores.

Art. $4^{\circ}$ Os valores dos emolumentos têm sua base de cálculo prevista nas tabelas e notas explicativas que integram esta Lei. (Estado De Mato Grosso Do Sul, 2005)

${ }^{4}$ Art. 236. Os serviços notariais e de registro são exercidos em caráter privado, por delegação do Poder Judiciário. (Brasil, 1988)
} 
ao sistema litigioso, dado que na perspectiva que visa à composição do conflito em bases consensuais é possível ampliar o objeto da discussão para alcançar outros pontos importantes para os interessados" (Tartuce, 2018, p. 105).

Nesse contexto, para que se alcance a aspiração de se obter caminhos viáveis e céleres para pacificação de conflitos, os procedimentos extrajudiciais devem, além de ser estimulados pelas normas legais, ter seus obstáculos removidos pelos operadores do direito.

Desse modo, ao se socorrer da via extrajudicial as partes esperam "o órgão responsável pela administração do conflito atuar segundo as técnicas previstas para tal mister, com eficiência e respeito em relação à vontade real das partes” (Tartuce, 2018, p. 107).

Nesse cenário, todo raciocínio até aqui desenvolvido, mostra que a extrajudicialização dos procedimentos bem como a desjudicialização dos instrumentos processuais são importantes institutos no que diz respeito a alternativas de solução consensual de conflitos pela via extrajudicial, por esse motivo deve-se ser ampliada sua utilização, de modo a consolidar e efetivá-la como um indispensável elemento do Sistema Jurídico, tudo em vista de promover a pacificação social.

\section{Considerações Finais}

O conceito de extrajudicialização se refere ao acesso à justiça de forma efetiva, uma vez que tal mecanismo procede apartado da esfera judicial, razão pela qual o conflito poderá ser resolvido em dias, afastando o monopólio do Judiciário devido à singeleza de determinados procedimentos, beneficiando as partes, bem como o Estado.

Nesse prisma, abordou-se que a inserção dos procedimentos extrajudiciais no núcleo jurídico brasileiro necessita de melhor adequação por meio do Poder Judiciário, visto que, como guardião do direito, deve promover meios de adequar tais ferramentas de suma importância para atingirem sua finalidade, desafogando o sistema judiciário e prestando significativos serviços à sociedade.

Deveras, observa-se que a população brasileira possui uma característica singular que diz respeito à grande procura pela tutela do sistema judicial, o que faz com que o Poder Judiciário se torne sobrecarregado de ações.

Nesse norte, constata-se que é preciso uma política pública efetiva que oferte diferentes mecanismos de pacificação de conflitos, evitando que eventuais contentas cheguem desnecessariamente ao sistema judiciário.

Destarte, a via extrajudicial tem o poder de solucionar o longo período de tramitação processual, pois representa uma importantíssima ferramenta para o acesso célere e efetivo à justiça, sendo que as inovações trazidas pelos diplomas legais do ordenamento jurídico representam um movimento importante, mas a jornada dependerá, especialmente, da transformação cultural na maneira de encarar o conflito e buscar soluções.

Embora seja a desjudicialização primordial para a efetiva administração do Judiciário, os altos custos de processamento em cartório desencorajam a população a optar por tal meio. Observa-se que isso ocorre devido ao poder delegado aos Estados para instituírem seus emolumentos, gerando desigualdade de taxas e, consequentemente, afastando as pessoas da via extrajudicial pela insegurança gerada, culminando em obstáculos a concreta adequação desse mecanismo de solução de conflitos.

Em linha de conclusão, constatou-se que determinados conflitos sociais podem ser resolvidos mediante a tutela extrajudicial. No entanto, é necessário, ainda, a criação de políticas públicas efetivas que incentivem a população a buscar a abordagem consensual para resolução de conflitos, em vista de promover a pacificação social.

Por conseguinte, se faz necessário o incentivo a adesão dos meios extrajudiciais como forma de solução de conflitos, com o objetivo de desobstruir as vias do Poder Judiciário, bem como promover a efetiva adequação de tais meios tornando a resolução de eventuais contendas mais céleres, justas e menos onerosas. 


\section{Referências}

ANOREG - Associação dos Notários e Registradores do Brasil. (2018). Anoreg/MS: Entenda a divisão de das taxas nos emolumentos dos cartórios. https://www.anoreg.org.br/site/2018/11/26/anoreg-ms-entenda-a-divisao-das-taxas-nos-emolumentos-dos-cartorios/.

Araújo, F. C. de. (2016). Curso de processo civil: parte geral. Malheiros, t. I.

Araújo, F. C. de. (2018). Curso de processo civil: procedimentos especiais. Malheiros, t. III.

Azevedo, S. N. de. (2015). O Registro de Títulos e Documentos. Edipucrs.

Barroso, L. A. \& Passamani, B. R. (2017). Usucapião extrajudicial: o procedimento para além da desjudicialização. Scientia Iuris. http://dx.doi.org/10.5433/2178-8189.2017v21n1p189.

Brasil. Constituição (1988). Constituição da República Federativa do Brasil: promulgada em 5 de outubro de 1988 . http://www.planalto.gov.br/ccivil_03/Constituicao/Constituicao.htm.

Brasil. Decreto-Lei n. 4.657. (1942). Lei de Introdução às normas do Direito Brasileiro. Diário Oficial [da] República Federativa do Brasil.

Brasil. Lei Federal n. 13.105. (2015). Código de Processo Civil. Diário Oficial [da] República Federativa do Brasil.

Brasil. Lei Federal n. 6.015. (1973). Dispõe sobre os registros públicos, e dá outras providências. Diário Oficial [da] República Federativa do Brasil.

Brasil. Superior Tribunal de Justiça. (2019) Recurso Especial n. 1.808.767/RJ. Relator Ministro Luis Felipe Salomão. Diário da Justiça [da] República Federativa do Brasil.

Conselho Nacional de Justiça (CNJ). Departamento de Pesquisas Judiciárias. (2019). Justiça em Números 2019. https://www.cnj.jus.br/wpcontent/uploads/conteudo/arquivo/2019/08/justica_em_numeros20190919.pdf.

Consultor Jurídico. (2019). Existência de testamento não inviabiliza inventário extrajudicial. Revista Consultor Jurídico. https://www.conjur.com.br/2019-out17/existencia-testamento-nao-inviabiliza-inventario-extrajudicial.

Dino. (2018) Rapidez e eficácia nos cartórios de notas retiram mais de 2 milhões de processos da Justiça. Portal de Notícias Terra. https://www.terra.com.br/noticias/dino/rapidez-e-eficacia-nos-cartorios-de-notas-retiram-mais-de-2-milhoes-de-processos-dajustica,d8d739cd31444d85c7bf02fbfbc9b25ehqil895v.html.

Estado de Mato Grosso do Sul. (2005). Lei Estadual n. 3.003, de 7 de junho de 2005. Diário Oficial do Estado de Mato Grosso do Sul.

Gil, A. C. (1999). Métodos e técnicas de pesquisa social. (5. ed.). Atlas.

Gonçalves, M. V. R. (2019). Direito Processual Civil Esquematizado. (10. ed.). Saraiva.

Guedes, J. C; Hauschild, M. L.; \& Helena, B. Z. S. (2019). A regulamentação pelo CNJ dos procedimentos extrajudiciais registrais. Revista Consultor Jurídico.

Gustin, M. B. de S.; \& Días, M. T. F. (2006). [Re]pensando a pesquisa jurídica: teoria e prática. (2. ed.) Del Rey.

Marchetti Filho, G. F. (2018). Os direitos fundamentais, a pacificação dos conflitos sociais e o Código de Processo Civil: o novo paradigma do processo civil em vista do acesso à justiça efetiva, justa, eficiente e adequada. Contemplar.

Marchetti Filho, G. F; \& Lemes, A. J. M. (2020). Desjudicialização: aquisição da propriedade imóvel pelo procedimento de usucapião extrajudicial. Revista Meritum. https://doi.org/10.46560/meritum.v15i1.7172.

Marquesi, R. W. (2018). Usucapião extrajudicial. (2. ed.) Juruá.

Pinto, J. (2019). Procedimentos extrajudiciais e o novo CPC. Portal de notícias CERS. https://noticias.cers.com.br/noticia/procedimentos-extrajudiciais-e-onovo-cpc/.

Riva, L. C. \& Guimarães, R. N. (2020). Inventário negativo judicial e extrajudicial: conselho nacional de justiça. Revista Quaestio Iuris. https://doi.org/10.12957/rqi.2020.41251.

Selltiz; Jahoda; Deutsch; Cook. (1974). Métodos de pesquisa nas relações sociais. Universidade de São Paulo (USP).

Tartuce, F. (2015). O Novo CPC e o Direito Civil. Método.

Tartuce, F. (2018). Mediação nos Conflitos Civis. (2. ed.). Método. 